Journal of Social Sciences (COES\&RJ-JSS)

ISSN (E): 2305-9249 ISSN (P): 2305-9494

Publisher: Centre of Excellence for Scientific \& Research Journalism, COES\&RJ LLC

Online Publication Date: $1^{\text {st }}$ January 2015

Online Issue: Volume 4, Number 1, January 2015

http://www.centreofexcellence.net/J/JSS/JSS Mainpage.htm

\title{
Impact of coaching on organizational learning and effectiveness
}

\author{
Lui-Yin KWAN \\ University of Wales, Newport, UK \\ C/O International Academy of Management, Hong Kong
}

\begin{abstract}
:
Many organizations keep recruiting coaching professionals for human resources development purpose and adopt coaching as an essential approach to achieve business goals because training and development is not enough for this era. Coaching is a dialogue process between the coach and the client (coachee). Coach asks questions and make coachee to realize his blind spots, enhance his strength and discover possibilities. Thus, coaching is adopted in order to create organizational effectiveness. The aim of the research is to understand and examine the impact of coaching on organizational learning and organizational effectiveness. Adoption of coaching as learning \& development purpose ables to generate individual learning in order to generate collective learning, ultimately results organizational learning. " $4 \mathrm{i}$ framework: intuiting, interpreting, integrating and institutionalizing" is also researched. It demonstrated the linkage of organizational learning, combination of individual's cognitive and behavioural operation. Personal learning lead Mentoring, Mentoring lead Career outcome is the proposed model. Qualitative research, focus group interview was conducted. Participants were the coaching service users who were working in different position from 4 different companies but in the same industry. The outcomes of the study indicate coaching as an effectiveness approach for both individual and organization development.
\end{abstract}

\section{Keywords:}

coaching, individual learning, organizational learning, organizational effectiveness, leadership, training \& development, learning \& development, human resources development.

\section{Citation:}

KWAN, Lui-Yin, (2015); Impact of coaching on organizational learning and effectiveness; Journal of Social Sciences (COES\&RJ-JSS), Vol.4, No.1, pp: 635-648. http://dx.doi.org/10.17632/yh86shzmzg.1 


\section{Introduction}

Since the beginning of $21^{\text {st }}$ century, many companies have an awareness of the need of training \& development (T\&D) repositioning because $21^{\text {st }}$ century is the era of "Knowledge Economic". Companies employed many knowledge workers, therefore, T\&D is not sufficient for core competency enhancement. Those companies' human resources department employed new employees with coaching skills and qualifications or hire external coaches in order to reinforce their departmental functions. This approach will encourage the transformational change from Human Resources Management (HRM) to Human Resources Development (HRD) because those companies will change their focus on development rather than management upon they experience the impact from coaching.

"Coaching does not train but develop peoples."

This new concept will drive human resources department to absorb coaching as another option of strategic intent in order to generate core competency and sustainable development. Because training focus on transfer of knowledge / skills for tasks in order to meet the standard required, and it is almost a one way methodology to cultivate employees' ability. However, coaching can inspire employees to be more clever, cultivate their ability so that they are capable to generate extraordinary performance; this is a kind of strategic capabilities for organizations. Managers and executives will use coaching to achieve personal and business goals because coaching can expend their mindset to figure out blind spots, aware their strength and limitation, discover more possibilities and options, understand gap between existing performance and ideal performance, get insight from cognitive progress, enhance the capability of self awareness. On the other hand, they are automatically eager to learn more in order to absorb the capability which can enhance performance and enrich outcomes, willing to take commitment of accountability and responsibility. Futhermore, managers and executives will use coaching as situational leadership style because they need to lead / manage their subordinates who are knowledge workers. Those subordinates might be an expert / specialists of any area / profession. This atmosphere demonstrated managers and executive would like to contribute more to organizations upon experience the impact of coaching. The ultimate outcome is getting ptersonal and business success which shape competitive advantages. And, those competitive advantages can contribute to organizational effectiveness enhancement.

Owing to the transformation of HRD as above mentioned, coaching will be adopted in order to create organizational development. Thus, this study will research following areas :-

\footnotetext{
a) To examine factors of how coaching can link with organizational learning.

b) To examine personal learning will result individual's satisfaction in order to enhance performance which will benefit organizational effectiveness.

c) To examine coaching can be applied not only in psychology discipline, and it can be applied in business as well.

d) To explore the correlation between coaching and below areas :

Leadership \& Management

Organizational culture

Personal mastery results competitive advantage
} 


\section{Rationale}

During the period before 1980's, supervisors / managers thought that their job is management. The main function is supervision of other peoples' works - doing things right and getting job done through other peoples. In post 1980's, they thought that they are leaders, their main function is leading other people in order to achieve visions - doing right things through other peoples. In other words, the core function of management is : Planning, Organizing, Leading \& Controlling within this period.

However, in the era of "Knowledge Economic" (The past president of the United States Bill Clinton declared that new era has been kick off in 1997 and he named the era as "Knowledge Economic"), information and technology will generate knowledge society which brings the revolutionary change. This change will break the old rules, regulations, styles and patterns of living ${ }^{1}$. Under this wave, managers / supervisors must act the role as a "Coach" so that they help their subordinates / colleagues to enhance effectiveness through both leadership and management. On the other hand, they will search the best leverage for individuals and organizations as well. New wave of management has been started.

Coaching started from 1980's in the United States, over the pass decades, the concept of coaching has aroused a revolution within management mindset around the world silently.

As per conservative prediction, there are more than 0.25 million professions working in coaching industry around the global.

Fortune500 indicate that more than $80 \%$ of senior employees (include supervisors and managers) of success enterprises have learnt coaching skill in order to enhance operating performance and staffs' potential.

In 2005, the report of "Chartered Institute of Personnel and Development" said that : $90 \%$ of the participants in the survey had attended coaching training.

Lancaster University Management School had adopted coaching as the formal program of their campus.

"According to above phenomenon, we are now living in a coaching century."

Charles Handy ${ }^{2}$ pointed out that, enterprises / organizations development like an organic life as similar as product life cycle which includes four stages : 1. Enterprises / Organizations start operating business; 2. Carry out development; 3. Performance and outcome will be reached at the peak; 4. Decline and died (Like human being : born, develop, growth, aging and died). Charles Handy described this organic life as "Sigmoid Curve". Therefore, we can not treat enterprises / organizations as substances (non-living things) anymore, we have to treat as holistic.

We can get insight from Handy's book ${ }^{2}$, he indicated that we have to plan a new sigmoid curve before the existing sigmoid curve turn into the stage of performance reaching the peak.

According to the below listed diagram, $1 \mathrm{~A}$ is the stage of beginning; $1 \mathrm{~B}$ is the next stage "The peak of organizations" outcome"; $1 \mathrm{C}$ is the last stage "Decline and died". The 
only way of maintaining organization's life is launching out another curve (Second Sigmoid Curve).

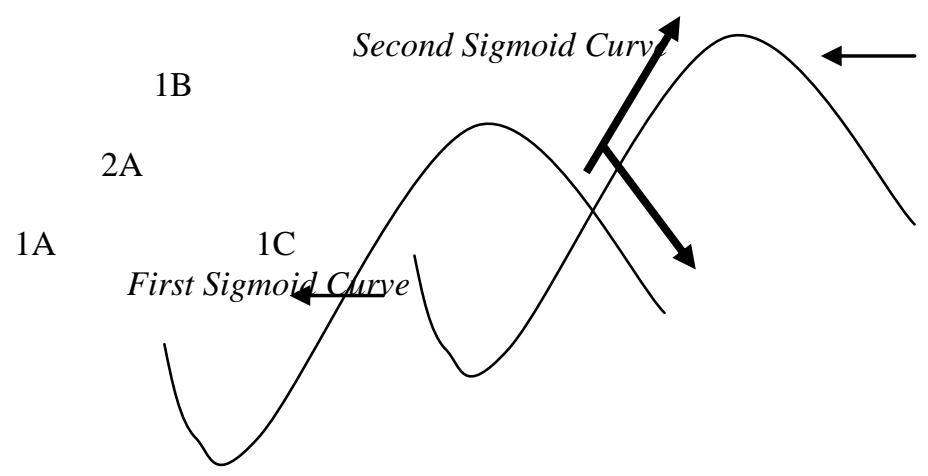

Fig. 1 Sigmoid Curve.

In order to maintain the organization's development and life, business leaders should considerate deeply and determine to launch "Second sigmoid curve" before "First sigmoid curve" step into decline and died stage in order to create sustainable growth. That curve may replace the old business model ${ }^{3}$, operating system, product, technology, value chain....etc. Thus, they should be capable to adopt new approach and capability ${ }^{4}$, create new core competency ${ }^{5}$ and decrease the impact of path dependency ${ }^{6}$.

\section{Literature Review}

According to the article: J. Swart, and J. Harcup, “'If I learn do we learn?': The link between executive coaching and organizational leanring," Management Learning. 44(4), 337-354 (2012), it identified coaching as a learning \& development approach to generate individual learning that it results collective learning, finally it will transfer to organizational learning. Those learning are factors of enhancing organizational effectiveness which is the objective of this research.

This article involves the correlation between executive coaching to organizational learning. It provided evidence that coaching can be a tool of learning \& development in both individual and organizational, this is able to generate contribution for organizational learning. It also proofed how coaching act as an approach of transformation of individual learning so that embed into collective learning (collective learning = collective level of learning by individuals) which results organizational learning. Because organizational learning is trigger organizational effectiveness enhancement.

This article focuses the mechanisms of individual learning converting into collective learning through individuals' concrete experiences ${ }^{7,8}$. It also pointed out two important themes. The first one, individual needs to learn wide spread ${ }^{9}$ within collective level (multilevel learning). The second one, individual learning co-relate to organizational outcomes. It described the process of accumulation at collective level of individual learning generating organizational leaning; thus, it named "learning in organizations". This demonstrated individuals experience the learning which is the only way of organizational learning ${ }^{9,10}$ for expected outcomes. 
This article quoted learning process will be operated via four processes : intuiting, interpreting, integrating and institutionalizing (4-i framework) ${ }^{11}$. These processes demonstrated the linkage of organizational learning by a psychological process and combination of individual's cognitive and behavioral operation. Individuals will learn subconsciously and share their ideas through "externalization" 12 . On the other hand, it discussed how genuine leaders will learn via genuine / reflective dialogue ${ }^{13}$ and aware the relationship between coaching and leadership, this approach will cultivate organizational culture which support and reinforce double-loop learning : feed-forward and feed-back ${ }^{14}$. These are the expected outcomes of this research.

Above mentioned areas involve mechanism of knowledge transfer, it is an important factor of how individual learning transfer to collective learning ${ }^{15}$. And, different kinds of knowledge need different types of transfer mechanisms ${ }^{16}$. They are the key success factor of generating organizational effectiveness.

This article also focuses the benefits of executive coaching due it can be used as an media for executive development; besides, line managers conducted coaching internally ${ }^{17-}$

${ }^{19}$ or hire external coaches to enhance productivity. Evidence of influencing organization in performance improvement ${ }^{20}$, productivity improvement ${ }^{21-23}$, increment of job satisfaction and staff performance / organization's cost savings ${ }^{19,24-26}$, creativity and innovative ability increment ${ }^{20}$ via coaching were increasing. Those benefits are the effect of organizational effectiveness enhancement.

Final, this article quoted coaching will result multiple outcomes which includes individual and collective level by improving performance and effectiveness, changing personal attitude and perception ${ }^{27}$. (Changing attitude and perception is important because cognitive deviation will produce psychological blind spots which will influence mindset, behavior and performance). There is a trend of increasing interests in how coaching works within influencing organizational change ${ }^{7,28-29}$.

According to the article: R. Gong, S.Y. Chen, and M.L. Yang, "Career outcome of employees: The mediating effect of mentoring," Social behavior and personality. 42(3), 487-502 (2014), it researched the linkage of personal learning and mentoring so that results career outcome ${ }^{30}$. Personal learning generated motivation effect which is acting a critical role for protégés, mentoring system may affect protégés' career development and outcome positively due keeping learning is able to have successful career.

This is the process to proof protégés get learning and satisfaction, then, give contribution to trigger organizational effectiveness.

\section{Personal learning Mentoring Career outcome}

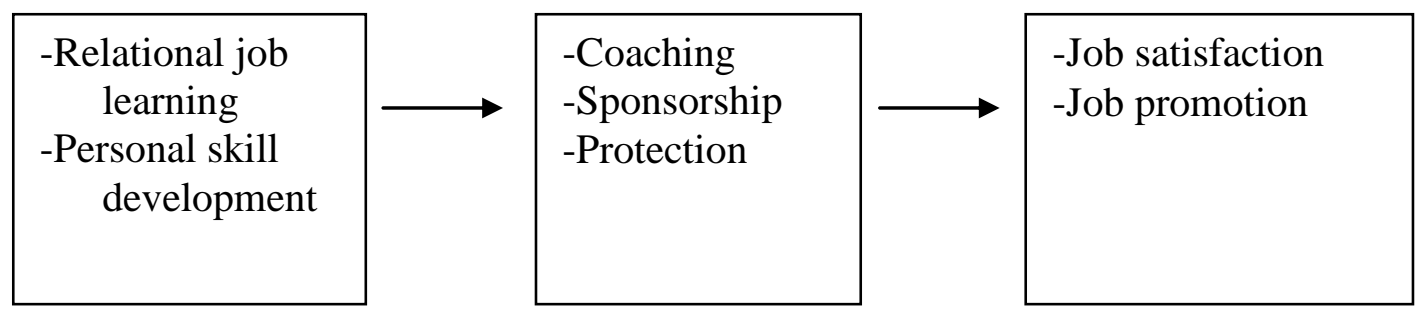

Fig. 2 Conceptual framework 
Personal learning can shape competence which includes knowledge, skills and attitude enhancement for career outcome contribution ${ }^{31}$. Protégés have to explore their interpersonal skills and collaborate with colleagues ${ }^{32}$ so that obtain personal learning. Because personal learning will arouse self-awareness and understanding consciously and unconsciously so that it can generate personal development ${ }^{33}$. This is the First Hypothesis : Relationship between employees' personal learning and mentoring.

This article focuses the Second Hypothesis : Relationship between mentoring systems as a mechanism to help protégés' success for career, this will generate organizational effectiveness through employees' professions and performance advancement by uplifting members' spirits and working quality, it demonstrated how the mechanism produce employees' satisfaction from psychological support and career advancement opportunity $^{34}$.

This article focuses the Third Hypothesis : The relationship between personal learning and career outcome in companies because it discussed how individual learning transform to personal mastery in order to shape competitive advantage (organizational level). It indicated four critical factors of personal learning and successful career outcome : career change, personal learning, organizational commitment and job satisfaction ${ }^{35}$. These are significant elements to enhance organizational effectiveness.

This article discussed the Forth Hypothesis : How employees practice mentoring as approach of relationship mediation between personal learning and career outcome.

Finally, this article quoted implications that management has awareness of employees' career outcome will be affected significantly by a system to improve personal learning which brings effect of employees' job satisfaction and enhancement. This is the objective of learning \& development is the way to generate competitive advantage in order to create organizational effectiveness.

\section{Research context and methods}

Owing to the purpose of this research was to identify the systems that transform individual learning into collective learning \& organizational learning, so that organizational effeciveness will be generated as a result. Therefore, focus group interview has been conducted, we interviewed 4 participants who give their consent prior interviews. Participants came from 4 different financial cum insurance companies and they were coachees (clients of coaching service) with experiences that had been coached. They have to answer research questions within the context of how coaching transform individual learning to organizational learning. Questions relate to : coachees' perspections of their coaching experience, how coachee had learnt (individual learning), how coaching generates collective changes in order to fulfill team goals, how individual learning outcomes translate to collective learning outcomes, and, another open-ended questions.

Table 1 Interview questions example for participants.

1. How long have you been coached?

2. How often you took up coaching?

3. What are your objectives of using coaching?

4. Please give an example that you have learnt personally from coaching?

5. How did you know that you had learnt as a result from coaching?

6. Please identify three most important tools used in the coaching which have 
helped you to learn?

7. Have you discovered any one in your team learn personally from coaching? If so, please give an example how they have learnt personally from coaching.

8. How did you know that they had leant?

9. Please give an example how you have used what you have leant from coaching to bring changes at a collective level.

10. How did you know that team members had learnt as a result?

11. Have you discovered any one in your team make collective changes after they have been coached? If so, please give an example of the changes they have made at a collective level.

12. What kind of processes or approach they had go through to make these changes at a team level?

13. How did you know that team members had learnt as a result?

\section{Mechanisms that transform individual learning into collective learning \& organizational learning: $4 \mathrm{i}$ framework}

All the participants demonstrated examples of the co-relation between individual learning, collective learning and organizational learning. Those examples include : cognitive and behavioral changes, mentailty and attitude changes, self-awareness increased, self-confidence and ability enhanced, team atmosphere cultivated, encouragement and motivation created, culture and leadership established.

\subsection{Intuiting}

The first element of the mechanisms that we identified was intuiting. Our findings demonstrate that participants' perception and cognition to coaching was the approach helping them to increase business result, to change attitude / behavior / mentality / attitude:

Enhance working ability in different areas includes team members recruitment, business result, team leading, team members business activities monitoring.

Let's say the level of recruiting, before I have been coached, I know nothing about recruitment and don't know what I have to do about recruitment. I only know that I need to recruit new agents for the company, I can be a manager once I recruited new agents; I have no idea what I need to do after recruitment. I know nothing about what kind of psychological preparation and changes I should have, and I have no idea what kind of skills should be enhanced before recruitment.

Enhance team members' accomplishment and let them achieve more business goal. For higher level, generate changes in attitude and in-depth changes. Let's say they will work automatically or figure out their goal of working clearly. The ultimate objective is more business fulfillment.

Head count of recruitment and team members' business result enhancement.

I want to improve myself, clear my block and solve the core problem which relate to my work and life. There is a metaphor, you can not have a long journey if you 
carry super heavy luggage. I can learn "let go", the person who can help me is me.

\subsection{Interpreting}

The second element of the mechanisms that we identified was interpreting. Data indicate that participants have changes of attitude / behavior / mentality / attitude; and, they increased self-awareness, enhanced self-confidence and ability. Participants realized that they obtain benefit and they have learnt from coaching and this is the frist step of proposed model (Personal learning) as well:

After I have been coached, it let me know one by one and show me the direction what I have obtain and what I have to learn in advance, then I can be a better manager. It will not tell you something what you should obtain, it will use multiple areas approach and many questions to facilitate you so that you will aware what type of leader you want to be, what kind of character / personality you are, and you will obtain something to use.

After I have been coached, I know that what the attitude of new members should have, how recruiter can help new members to success. Meanwhile, I would like to demonstrate the benefit of financial planning industry to my relatives because it can achieve career goals and life goals. This is my drive of conducting recruitment now.

The most significant change is behavior, one of my team member applied what he has leranrt in his work including words and content which he spoke, and add new working model together with existing working model.

Another team member aware how many weekly activities he should made, even his activities are not enough at this moment but he has an awareness of the standard and keep putting effort to achieve.

It is the result of the change of team members' mentality and behavior. Before they have been coached, they have no awareness to recruit new members. After they have been coached, they have awareness to recruit new members. Second, they aware they have to increase activity quantity. Besides, according to skill level, team members improved their content of speaking.

Personal and team business performance has been enhanced, personal changes such as self-confidence and working ability enhancement. For example, young members have more confidence and they act initiative after have been coached. Their working ability has been improved; they have more confidence and better performance in presentation and contribute suggestions during the meeting.

I can get better performance and business outcome, have an attitude which eager to insist on working, have positive mind to enhance performance and see the significant improvement.

Yes, one team member who was a university fresh graduate student, he changed a lot. Before he has been coached, he has not enough self-confidence and not acted initiative, but he used 3 years to be a one of management now, it is very fast. He has stronger self-confidence and has positive mind, coaching let him to work 
automatically.

Team member got better performance and business outcome; he obtained a better self-being and self-confidence, attitude changes. He also has positive mind and act initiative.

I am able to get more business result and solve my problems. My mentality, mindset and thinking way will be changed; those changes will influence my behavior so that performance and result will be enhanced.

Yes, Before my team members have been coached, they will feel uncertain when they call clients for appointment. After they have been coached, they got some mindset and working pattern so that they are able to get breakthrough.

Team members' business result has been enhanced. They have change of attitude, and, have breakthrough as well.

Let's say our recruitment activity; we will practice mentality preparation for our team member prior recruit new colleagues. I think that we should have a clear mind set prior determine any concrete action plan.

Under direct observation, we can see that team members will repeat their problems or not; if they had solved their problems, they will have better performance and business results.

I had learnt coaching skills from my coach and his questioning skills, I found out what kind of problem I'm facing now. Coaching can help me to expend my thinking which according to problems I have to solve. I am able to discover the answers / solutions from myself during coaching process. I think that the coach gave coachee pressure in order to generate coachee's actions, or, coach use some approach to facilitate / push coachee's drive, so that the drive can generate actions for improvement. No actions, coaching is not worth doing. The drive is very important, it is the dynamic which coachee will eager to change; otherwise, why coaching?

Peoples like to discover their changes by themselves but hate to be told.

\subsection{Integrating}

The third element of the mechanisms that we identified was integrating. Participants demonstrated their individual learning transformed into collective learning (team learning). Those datas indicate individual learning generated effects of cultivating team atmosphere, creating encouragement \& motivation, establishing culture \& leadership. And, this is also the step of proposed model (Personal learning lead Mentoring):

According to my manager's team, the members who have been coached will use divergent mode in order to let other members to know what they have learnt from coaching. We have used many promotion and facilitation to bring out the benefit we got, so that we can attract more other members to use what we have learnt from coaching.

According to my team, we have discussed to identify the mentality and tools what we have learnt and discussed if they are suitable. If so, we will use those 
mentality and tools together, and, evaluate the effect weekly.

We will let our team members to think something very often, for example: What is the purpose of our job? We will use questioning to help and use exercise to facilitate them. Besides, we will launch team building activity; relationship of each colleague will be closer, they will be more positive to get more business result.

Yes. My team members had a clear goal and stronger self-confidence after they had been coached. Those results should be done by their effort putting; they did all their best to achieve. Coaching surely helps.

\subsection{Institutionalizing}

The fourth element of the mechanisms that we identified was institutionalizing. Our findings demonstrated that collective (team) learning generated the effect of organizational learning; and, this is the step of proposed model (Mentoring lead Career outcome). Datas indicated that this effect is the key factor to generate leadership and enhance team performance, personal career outcome transformed to organizational outcome:

Yes, my team members have learnt. One member's learning can motivate him but can not last for longer time. Another member's learning can last for long time because he eager to find method to make the effect stay long within.

There are two levels, when I am a team player of my manager's team, I will use what I have learnt according to the situation and share my learning with other team players.

When I am the leader of my team, we will use what we have learnt together so that effect can be more efficient.

I will practice weekly work revision with my team members to evaluate their performance. Besides, I will talk with them to see they are still using what they have learnt or not.

My team members learnt that activities lot weekly review is useful; they had review by themselves and also asked me to review as well.

Besides, my team members have awareness that they should have at least one to two appointments for recruitment weekly. Before they have been coached, they don't have this awareness and they only work for their individual business, but they have awareness now after coached.

We will measure it terms of business result; colleagues will improve result not a single time, they will improve result very steady with their changes.

Some other team members worked with my team will practice many exercises and achieve some goals together; finally, they will get positive mentality in work to influence and motivate our team members. They will take initiative as team leaders as a culture; leaders influence members so that members influence other members because other members' be positive mind. It is a good culture because 
those atmospheres of influence are for team.

My manager used coaching to create an atmosphere to enhance business results and head count of recruitment. He created a culture to encourage all team members' participation of activities.

I think that it is a culture. We might not have improvement upon we have been coached one time only, we need a long term culture to change though by adopt coaching. For example, we will have changes for business strategy.

Besides, we will have awareness to fine tune incentive in order to generate motivation and encouragement effect, and, we will allocate manpower according to our department's recruitment activity upon we have been coached.

My team members dare to work hard, then, they earn satisfaction and proud of their contribution even whatever results they obtained finally. It will be a gear system, one gear moved will contribute dynamic to the other gears continuously. They discover their strength and ability to get job done. Before they have been coached, they had many excuses; but they had intrinsic satisfaction now and will achieve goal continuously. Moreover, they had discovered their own methods to achieve goal, it is a sustainable effect. According to my industry, if you can sustain your goal fulfillment ability, you can build up self-confidence.

I applied coaching skills in free talk with my colleagues who didn't feel well. I facilitate them to see something which is positive because I do believe deeply that there are meaning and purpose of each thing happen.

Someone can not leave from trouble; but he can escape if you give him a hand. I help them to discover their own solution by themselves; then, they are able to help by themselves when they need help again.

Yes. Team members had self-confidence enhancement and others praised them, and, team members got intrinsic satisfaction. Those changes will generate influence in the team; members will feel the positive energy when listening to others' sharing.

Those members can be a role model who can influence others to work better and obtain recognition; otherwise, you will not get client and deal. Other team members, will learn working pattern from role model as well; the right way they learnt, job can be done.

They shared their pathway of heart and soul as a way to influence other team members, if you can do it, other will praise you.

\section{Conclusion}

This research encourages our understanding of the corelation between individual learning and collective learning, ultimate organizational learning generated. Through coaching, it inspires individuals' changes of cognition and behavior; because individuals had self-awareness so that they are able to determine which mentality and attitude can help them to obtain personal performance improvement and beter business outcome. They are able to distinguish positive mindset and thoughts in order to achieve their goals and 
accompolishment. Those experiences are individuals' learnings in order to produce many possibilities, those learnings also make individuals to become clever and brilliant. Therefore, individual development can be happen.

Coaching acted the role of mentoring which encourage thinking. Thinking process generated mindset level enhancement, individuals' self-awareness can be re-inforced through thinking. Therefore, individuals are able to realize that their existing mental state, cognition \& behavior are appropriate and effective for their goals or not. Opposite, coaching helped individuals to figure out their cognitive deviation which makes psychological blind spots. This is another type of self-awareness because discovery of psychological blind spots makes individuals to find out more options and possibilities to achieve their objectives of taking coaching. The critical factor is coaching generating actions which can generate effectiveness; individuals discovered their own options and actions according to their capability level which are appropriate, effective, suitable to the circumstance. This is the drive to trigger off individuals' dynamic and desire of actions because those actions are the way of producing improvement, accompolishment and success.

Mentoring lead career outcome is the most important value of this research because it includes satisfaction (intrinsic satisfaction) which is good for leadership and management. Intrinsic satisfaction is the product of job satisfaction through excellent leadership style, individual development and management. It is the effectiveness of well practicing situational leadership, managers / executives will lead their subordinates to perform job well according to their attitude / skills / knowledge / capabilities. As the result of adopt coaching above mentioned, those managers / executives will practice coaching in their teams in order to achieve more business outcome, accomplishment and enhance effectiveness. This approach will be the main stream of the trend of individual and organizational development in order to replenish the limitation of training and development. Individuals' learning through coaching is an active way better than training. During coaching process, individuals learnt through their dialogue with coaches, this is an interactive methodology. However, training is one-way methododogy because training objectives are only for "transfer of skills" or "transfer of knowledge". It is seldom to consider individuals' level of thinking ability because management didn't realize many employees were knowledge workers now. According to above research findings, individual learning played the change agent to influence teams so that teams can obtain collective learning in order to generate positive changes. Multi quantites / level of team learning at the same time will produce leverage effect which generate organizational learning. Finally, those practice were the core competency, organizational culture, leadership style and strategic capability which shape sustainable competitive advantages; and, the ultimate purpose is organizational effectiveness enhancement.

\section{References}

1. A. Toffler, The Third Wave, William Collins \& Co. Ltd (1980).

2. C. Handy, The Empty Raincoat, Arrow Business Books (1994).

3. D.J. Teece, "Business Models, Business Strategy and Innovation," Long Range Planning. 43(2-3), 172-194 (2010).

4. M. Porter, "From Competitive Advantage To Corporate Strategy," Harvard Business Review. 65(3), 43-59 (1987). 
5. C. Prahalad, and G. Hamel, "The core competence of the corporation," Harvard Business Review. 68(3), 79-91 (1990).

6. G.. Johnson, K. Scholes, and R. Whittington, Exploring Corporate Strategy, Text \& Cases ${ }^{T H}$ Edition, Prentice Hall (2008).

7. A.M. Grant, "It takes time: A stages of change perspective on the adoption of workplace coaching skills," Journal of Change Management. 10(1), 61-77 (2010).

8. D.E. Gray, and H. Goregaokar, "Choosing an executive coach: The influence of gender on the coach-coachee matching process," Management Learning. 41(5), 525-544 (2010).

9. M. Popper, and R. Lipshitz, "Organizational learning: Mechanisms, culture, and feasibility. In: Grey C and Antonacopoulou E (eds)," Essential Readings in Management Learning. London: SAGE, 37-52 (2004).

10. M. Popper, and R. Lipshitz, "Organizational learning mechanisms: A cultural and structural approach to organizational learning," Journal of Applied Behavioural Science. 34(2), 161-178 (1998).

11. M.M. Crossan, H.W. Lane, and R.E. White, "An organizational learning framework: From intuition to institution," Academy of management Review. 24(3), 522-537 (1999).

12. I. Nonaka, "A dynamic theory of organizational knowledge creation," Organization Science. 5(1), 14-37 (1994).

13. D.E. Gray, "Facilitating management learning: Developing critical reflection through reflective tools," Management Learning. 38(5), 495-517 (2007).

14. D. Mazutis, and N. Slawinski, "Leading organizational learning through authentic dialogue," Management Learning. 39(4), 437-456 (2008).

15. M. Xavier, and R. Salomon, "Knowledge transfer capacity and its implications for the theory of the multinational corporation," Journal of International Business Studies. 34(4), 356-373 (2003).

16. H. Bresman, J. Birkinshaw, and R. Nobel, "Knowledge transfer in international acquisitions," Journal of International Business Studies. 30(3), 439-462 (1999).

17. R. Agarwal, C.M. Angst, and R. Magni, "The performance effects of coaching : A multilevel analysis using hierarchical linear modeling," International Journal of Human Resource Management. 20(10), 2110-2134 (2009).

18. R.E. Boyatzis, M.L. Smith, and N. Blaize, "Developing sustainable leaders through coaching and compassion," Academy of Management Learning \& Education. 5(1), 825 (2006).

19. A.D., Ellinger, A.E., Ellinger, D.G. Bachrach, et al, "Organizational investments in social capital, managerial coaching, and employee work-related performance," Management Learning. 42(1), 67-85 (2011).

20. K. Mulec, and J. Roth, "Action, reflection, and learning: Coaching in order to enhance the performance of drug development project management teams," $R \& D$ Management. 35(5), 483-491 (2005).

21. S. Kampa, and R.P. White, "The effectiveness of executive coaching: What we know and what we still need to know. In: Lowman RL (ed.)," The California School of Organizational Studies Handbook of Organizational Consulting Psychology. San Francisco, CA: Jossey-Bass. 139-158 (2002).

22. R.R. Kilburg, "Trudging toward Dodoville: Conceptual approaches and case studies in executive coaching," Consulting Psychology Journal: Practice and Research. 56(4), 203-213 (2004). 
23. J.W., Smither, M., London, R. Flautt, et al, "Can working with an executive coach improve multi source feedback rating over time? A quasi-experimental field study," Personnel Psychology. 56(1), 23-44 (2003).

24. A.D. Ellinger, "Antecedents and consequences of coaching behaviour," Performance Improvement Quarterly. 16(1), 5-28 (2003).

25. A.D. Ellinger, and R.P. Bostrom, "Managerial coaching behaviours in learning organizations," Journal of Management Development. 18(9), 752-771 (1999).

26. A.D. Ellinger, A.E. Ellinger, and S.B. Keller, "Supervisory coaching behaviour, employee satisfaction, and warehouse employee performance: A dyadic perspective in the distribution industry," Human Resource Development Quarterly. 14(4), 435458 (2003).

27. D.T. Hall, K.L. Otazo, and G..P. Hollenbeck, "Behind closed doors: What really happens in executive coaching," Organizational Dynamics. 27(3), 39-53 (1999).

28.J.M. Hunt, and J.R. Weintraub, The Coaching Organisation, Thousand Oaks, CA: SAGE (2007).

29. D.R. Stober, "Making it stick: Coaching as a tool of organizational change," Coaching: An International Journal of Theory, Research and Practice. 1(1), 71-80 (2008).

30. J. Jones, "An analysis of learning outcomes within formal mentoring relationships," International Journal of Evidence Based Coaching and Mentoring. 10(1), 57-72 (2012).

31. K.E. Kram, Mentoring at work : Developmental relationships in organizational life, University Press of America (1988).

32. S. Gherardi, D. Nicolini, and F. Odella, "Toward a social understanding of how people learn in organization," Management Learning. 29(3), 273-297 (1998).

33. M. Rawson, "Learning to learn : More than a skill set," Studies in Higher Education. 25(2), 225-238 (2000).

34. S. Aryee, Y.W. Chay, and J. Chew, "The motivation to mentor among managerial employees : An interactions approach," Group and Organization Management. 21 (3), 261-277 (1996).

35. M.C. Higgins, \& K.E. Kram, "Reconceptualizing mentoring at work : A developmental network perspective," Academy of Management Review. 26(2), 264288 (2001).

Lui-Yin Kwan is a graduate student of MBA at the University of Wales, Newport, UK. $\mathrm{He}$ received his $\mathrm{BA}(\mathrm{Hons})$ degree in Business Administration from the University of Coventry, UK in 2012. He is a corporate coach and corporate trainer respectively, he received his RCC (Registered Corporate Coach) professional qualification from the Worldwide Association of Business Coaches, Canada in 2006. 